\title{
Could inter-agency working reduce emergency department attendances due to alcohol consumption?
}

\author{
J Benger, ${ }^{1}$ R Carter $^{2}$
}

${ }^{1}$ University of the West of England, Faculty of Health and Social Care, Bristol, UK;

${ }^{2}$ Academic Department of Emergency Care, United Bristol Healthcare Trust, Bristol, UK

Correspondence to: Dr J Benger, University of the West of England, Faculty of Health and Social Care, Glenside Campus, Bristol BS16 1DD, UK; Jonathan.Benger@uwe.ac.uk

Accepted 21 November 2007

\begin{abstract}
Background: Excess alcohol consumption and associated harms in terms of health, crime and disorder have been highlighted by the government and media, causing considerable public concern. This study quantified the number of patient attendances at an urban adult and children's emergency department (ED) directly attributable to alcohol intoxication, and investigated ways in which the inter-agency sharing of anonymised information could be used to design, implement and monitor interventions to reduce these harms.
\end{abstract}

Methods: Intoxicated patients attending either the adult or children's ED were prospectively identified by qualified nursing staff and anonymised data collected by a dedicated researcher. Collaboration and data sharing between health, police, social services, university experts and local authorities was achieved through the establishment of steering and operational groups with agreed objectives and the formation of a shared anonymised database.

Results: The proportion of patients attending the ED as a result of alcohol intoxication was $4 \%$ in adults and $<1 \%$ in children. $70 \%$ of patients were male, with a mean age of 30 years, and $72 \%$ attended between 20.00 and $08.00 \mathrm{~h}$. The most common reason for ED attendance was accident (34\%), followed closely by assault (30\%). $27 \%$ of patients had done most of their drinking at home, $36 \%$ in a pub and $16 \%$ in a nightclub. Inter-agency collaboration proved highly successful: pooling of anonymised data created a much clearer picture of the extent of the problem and immediately suggested strategies for intervention.

Conclusions: The initiative to achieve inter-agency collaboration and data sharing was highly successful, with clear potential for the development and implementation of interventions that will reduce ED attendance due to excess alcohol consumption.

Recent research has suggested a sharp increase in alcohol consumption, particularly among young adults. ${ }^{1}$ A UK Government report in 2003 put the total cost to the NHS of alcohol-related injuries and illnesses at up to $£ 1.7$ billion a year, with alcohol-related crime, assaults and disorder costing a further $£ 7.3$ billion. $^{2}$ It is estimated that $5 \%$ of young men and $8 \%$ of young women aged 18 24 years are likely to drink at "high risk" levels. ${ }^{3}$

Excess alcohol consumption is associated with physical and social harm to drinkers and those around them. In nearly half of all violent incidents in 2001/2, victims believed offenders to be under the influence of alcohol. ${ }^{4}$ The Alcohol Harm Reduction Strategy for England, published by the
Prime Minister's strategy unit on 15 March 2004, contains measures to address the range of harms caused by alcohol misuse in England. ${ }^{5}$ These include specific legislation to tackle alcohol-related crime-such as the Licensing Act 2003 and the Criminal Justice and Police Act 2001-which makes it easier for local authorities to restrict antisocial public drinking in specified places, to close down unruly licensed premises and to further restrict drunkenness on licensed premises. However, despite this change in government strategy, there persists a strong public perception of a spiralling trend towards unrestrained alcohol consumption, particularly within urban areas, ${ }^{6}$ and further research is required to accurately determine the prevalence of this behaviour while developing methods to control the associated harms.

Alcohol Concern comment that, while people see drinking as being just about personal choice, the reality is that our already overstretched emergency services are being left to cope with the consequences of weekend excesses. ${ }^{7}$ Alcohol is therefore a prime concern for both health and police services, but formal collaboration between these two agencies has not been investigated or evaluated despite government efforts to encourage inter-agency working at a local level. A recent initiative in Cardiff, however, showed that the judicious sharing of information about locations and times of violence derived from patients in emergency departments (EDs) was a powerful and effective means of targeting police and other local resources to bring about a reduction in violence. ${ }^{8}$ These principles, which have been proved to be effective against violent crime, may well hold true for excessive and harmful alcohol use.

The objectives of this study were:

1. to quantify the number of patient attendances at the EDs of the Bristol Royal Infirmary and Bristol Royal Hospital for Children that are attributable to alcohol intoxication;

2. to investigate ways in which anonymous information on alcohol consumption leading to ED attendance can be successfully collected and shared with other agencies in order to promote a co-ordinated approach to reducing the harms associated with excess alcohol consumption.

\section{METHODS}

This single-centre study was undertaken in the EDs of the Bristol Royal Infirmary and the Bristol Royal Hospital for Children, both part of the United Bristol Healthcare Trust. These departments serve 
an inner city population, particularly Bristol city centre and waterfront where there is a high concentration of nightclubs and bars. The combined ED attendance is approximately 90000 patients per year. This study commenced in September 2005 for an initial period of 4 months.

\section{Objective 1}

In order to quantify the number of patients attending as a result of alcohol intoxication, a robust method of detection was required. Measurement of blood alcohol, either directly or by breath testing, was considered but discarded as ethically unacceptable. It was also apparent that simply asking people how much alcohol they had drunk would lead to under- or overreporting. It was therefore decided that qualified nursing staff would be asked to identify patients who, in their view, were intoxicated on arrival at the ED and where their attendance could be reasonably attributed to this intoxication, and also patients who attended the ED on the day following a period of alcohol intoxication with a presenting complaint that could be reasonably attributed to this intoxication. Inevitably, this approach relied on the judgement of professional staff, but it was felt that such staff would often be in a better position to judge intoxication and its consequences than the patients themselves.

A small sticker was designed and qualified nursing staff were asked to apply this to the notes of every included patient attending the ED during the 3-month study period. This sticker, printed in a bright colour, made the notes readily visible to the project's research nurse who then examined these notes further. To maximise compliance, the sticker contained two simple questions (table 1) which were completed by the assessing nurse.

During the first month of the project, staff were educated in the use of the sticker and it was then introduced into routine use during months 2, 3 and 4. Education and support were provided throughout the study, and all patient notes were retrospectively reviewed by the research nurse to ensure that no potential patients were missed and to provide immediate feedback and encouragement to all staff. During month 2 compliance was incomplete, requiring additional input to ensure that all eligible patients were included during months 3 and 4.

Data from the stickers were extracted into an Excel spreadsheet for further analysis using descriptive statistics. These data were anonymised at the point of extraction to allow ethical sharing with other agencies.

\section{Objective 2}

Two inter-agency groups were established: a larger steering group comprising representatives from health (both emergency health care and public health), police, social services, university

Table 1 Sticker used for data collection

\begin{tabular}{|c|c|c|}
\hline \multicolumn{3}{|c|}{ Academic Department of Emergency Care Alcohol Consumption Study } \\
\hline In your view is this patient: & \multicolumn{2}{|c|}{ Where did they do most of their drinking? } \\
\hline A1: Drunk and incapable & B1: Pub & $\cdots$ \\
\hline A2: Drunk and accident & B2: Club & \\
\hline A3: Drunk and assault & B3: Street & $\cdots$ \\
\hline A4: Drunk and self-harm & B4: Home & \\
\hline
\end{tabular}

When a tick was placed in box B1, B2 or B3 the staff member was also asked to enter the name of the pub, club or street where the patient had done most of their drinking. experts and local authorities, and a smaller operational group comprising policing, emergency health care and public health. These groups met several times during the project to develop a shared anonymised database relating to alcohol use and its associated harms in order to:

- describe and delineate the scale of the problem;

- inform tactical decisions within the agencies involved;

- inform strategic and planning decisions relating to alcohol within the city;

- monitor progress over time and the effectiveness of any interventions.

\section{RESULTS}

\section{Objective 1}

The number of adult patients attending the ED as a direct result of alcohol consumption was 114 (2.3\%) in October 2005, 174 (3.8\%) in November 2005 and 204 (4.1\%) in December 2005. The identified patients were categorised into four groups: (1) drunk and incapable; (2) drunk and accidentally injured; (3) drunk and involved in assault; (4) drunk and self-harmed. The number of patients falling into each of these groups during the study period is shown in fig 1 .

Three hundred and forty-four patients (70\%) were men and the mean age was 30 years; $354(72 \%)$ attended between the hours of 20.00 and $08.00 \mathrm{~h}$. One hundred and thirty-three patients $(27 \%)$ had done most of their drinking at home, 177 (36\%) had done most of their drinking in a pub and $79(16 \%)$ in a nightclub. An additional 15 adults (3\%) had done most of their drinking on the street. Eighty-eight patients (18\%) were unable to supply this information accurately.

The study included the ED of the Bristol Royal Hospital for Children where children under the age of 16 years are treated. On average there were 2.5 attendances per month due to alcohol (usually children who were drunk and incapable following alcohol excess). This is an attendance rate of less than 1\%. In the adult emergency department of the Bristol Royal Infirmary (treating patients aged 16 years and over), 13 persons aged 16 or 17 attended the ED as a result of alcohol excess during the month of December $(0.3 \%$ of all patient attendances and $6.4 \%$ of those attending as a result of alcohol).

\section{Objective 2}

During the course of the study four inter-agency meetings occurred: one meeting of the steering group and three meetings of the operational data management group. It was apparent from the outset that there was much to be gained by working in

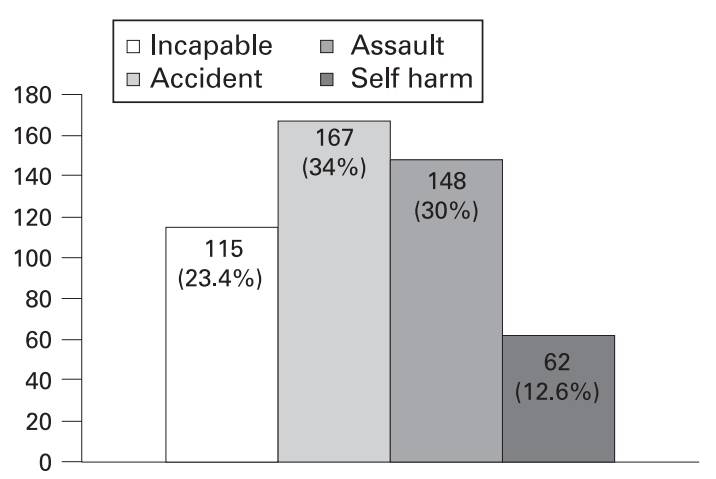

Figure 1 Types of alcohol-related presentations during October, November and December 2005. 
partnership to share data and consider appropriate interventions to reduce irresponsible alcohol consumption and thereby:

- improve individual health with a reduction in ED attendance;

- improve public health by reducing the long-term consequences of alcohol use;

- reduce crime, assault and disorder;

- improve public confidence in the city centre and night-time economy.

By pooling anonymised data that related to the location, time and type of each incident between health and policing, it was possible to build a much clearer picture of the extent of the problem and develop possible strategies for intervention.

Only $20 \%$ of assault victims report their crime to the police, ${ }^{4}$ so the addition of ED data provided further valuable information. Furthermore, when the health and police datasets were compared, a striking concordance was noted in that the three city centre premises causing most trouble for the police were also those causing most attendances at the ED:

\section{Premises 1 (nightclub: capacity 1650)}

This was the most featured club in the study with $10 \mathrm{ED}$ attendances in the months of October and November (5 assaults, 2 intoxicated, 1 spiked drink and 2 accidents), 14 calls to 999 and 8 violent offences logged by the police during the same period. However, following intervention by the police at the end of November, no further ED attendances were logged during the month of December, suggesting that police intervention had been effective.

\section{Premises 2 (bar with late licence: capacity 600)}

This was a recognised trouble spot with $8 \mathrm{ED}$ attendances during the 3 months of the study ( 3 accidents, 3 intoxicated, 2 assaults), 2 of which were in underage drinkers. During the same period there were 23 calls to 999 and 8 violent offences logged by the police. Police action was discussed and planned by the operational group.

\section{Premises 3 (pub and club: capacity 1100)}

During the 3 months of the study there were $8 \mathrm{ED}$ attendances (3 assaults and 5 accidents), 17 calls to 999 and 9 violent offences logged by the police. Attendances were noted to be on the increase month by month.

The inter-agency meetings identified several areas for further co-operation, development and research, and it was also apparent that they would be ideally placed to monitor the impact of any intervention. It was proposed that complementary data from health and policing be presented at Licensing Committee hearings, with the ultimate sanction of withdrawing the license from troublesome premises. Before taking such action, however, it was agreed that joint health and policing meetings would be held with the managers of problem premises to discuss the issues and agree strategies for improvement. A similar approach has been shown to be effective when dealing with violent crime in Cardiff during the Targetting Alcohol-related Street Crime (TASC) initiative. ${ }^{8}$

\section{DISCUSSION}

In this study the incidence of ED attendance directly attributable to alcohol consumption was $4 \%$ in adults and $<1 \%$ in children. Inter-agency collaboration was successfully developed and proved highly promising; pooling of anonymised data created a much clearer picture of the extent of the problem and immediately suggested strategies for intervention that could be monitored by the agencies involved.

Interestingly, our results do not approach the often quoted figure that $30-40 \%$ of all ED attendances are directly attributable to alcohol consumption. ${ }^{9-11}$ This discrepancy may be due to differences in the identification and classification of alcohol users. Furthermore, we included only those with acute intoxication and not the longer-term consequences of alcohol use, although this alone is unlikely to account for such a large discrepancy.

An obvious weakness of this study is the reliance on the professional judgement of ED nursing staff. Individuals may be assaulted or suffer accidents at any time of the day or night, regardless of whether alcohol has been consumed, and we therefore required a measured judgement from the qualified nurse assessing each patient.

Bristol has a diverse nightlife and it also has a wide variety of drinking establishments. It is unfair to simply measure the number of incidents occurring in premises without taking capacity into account. Other authors have adjusted for capacity when identifying "problem premises", , and we would concur with this approach. We propose that the rate of crime, disorder or acute healthcare use be expressed as the number of incidents per 100 person capacity within a specified time frame. By presenting the results in this way, it is possible to distinguish large clubs with a good record from small pubs with a poor record. Further analysis of the features of "problem premises" could build upon previous work relating to bars. ${ }^{12}$

Perhaps the most successful part of this research was the inter-agency working and anonymised data sharing. We initially convened a high level multi-agency steering group to consider common problems in relation to acute alcohol consumption. This meeting identified key objectives and plans for action, integrated with other initiatives in the city, which were then carried out by the smaller operational group. Unfortunately, it was not possible to specifically test intervention strategies within the limited timescale of this project, but the effectiveness of data sharing and the potential for information gathering and intervention were clearly demonstrated.

A great deal remains unknown regarding the behaviour of individuals and groups drinking in an urban environment, and this is a highly promising area for future qualitative and quantitative research. It is known that direct feedback to managers of premises and some forms of additional incentive can reduce the harms associated with heavy alcohol use, ${ }^{13}$ but the effects of proactive media publicity, the powers available under new licensing laws and practical measures in areas of high concentration drinking remain largely unexplored.

\section{CONCLUSION}

Excessive alcohol consumption, particularly among young people, is a subject of considerable concern to government and the public, with associated harms to individuals and society. We have quantified the number of patient attendances at an inner city adult and children's ED directly attributable to alcohol intoxication, and found this figure to be in the region of $4 \%$ of all ED attendances for adults and $<1 \%$ for children under 16 years. This is lower than previous reports, possibly due to a requirement that included patients to be both intoxicated and attending the ED as a result.

Exploratory work to investigate ways in which anonymised health care information can be collected and shared with the police in order to reduce ED attendance in an urban setting proved highly successful, with great promise for effective intervention and monitoring in the future. 
Acknowledgements: The authors are indebted to the nursing staff of the Emergency Department at the United Bristol Healthcare Trust for their assistance with data collection, particularly Rebecca Hoskins.

Funding: This study was funded by a grant from the Alcohol Education and Research Council, under the Council's small grants scheme.

Competing interests: None.

\section{REFERENCES}

1. Chief Medical Officer. Liver cirrhosis - starting to strike at younger ages. London: Department of Health, 2001

2. UK Home Office. http://www.cabinetoffice.gov.uk/strategy/work_areas/ alcohol misuse/interim.aspx (accessed 8 April 2008).

3. Newburn T, Shiner M. Teenage kicks? Young people and alcohol: a review of the literature. York: Joseph Rowntree Foundation, 2001.

4. British Crime Survey. 2002. http://www.homeoffice.gov.uk/rds/crimeew0203.html (accessed 8 April 2008).

5. Prime Minister's Strategy Unit. Alcohol harm reduction strategy for England. London: Prime Minister's Strategy Unit, 2004.
6. Daily Mail Newspaper. Alcohol abuse: the facts about binge drinking. 12 May 2004. http://www.dailymail.co.uk/pages/live/articles/health/ thehealthnews.html?in_article_id $=302531$ cin_page_id $=1797$ (accessed 10 April 2006).

7. Alcohol Concern. Alcohol's on everyone's lips. London: Alcohol Concern, 2001.

8. Warburton AL, Shepherd JP. Development, utilisation and importance of accident and emergency department derived assault data in violence management. Emerg Med J 2004;21:473-7.

9. Department of Health. Alcohol misuse interventions. Guidance on developing a local programme of improvement. London: HMSO, 2005.

10. Cabinet Office. Interim analytical report. London: the Prime Minister's Strategy Unit, 2003.

11. BBC News. AqE treats ' $1 \mathrm{~m}$ drinkers per year'. http://news.bbc.co.uk/1/hi/health/ 4183881.stm (accessed 10 April 2006).

12. Graham K, Homel R. Creating safer bars. In: Plant MA, Single E, Stockwell T, eds Alcohol: minimising the harm: what works? London: Free Association Books, 1997:171-92.

13. Saltz RF. Prevention where alcohol is sold and consumed: server intervention and responsible beverage service. In: Plant MA, Single E, Stockwell T, eds. Alcohol: minimising the harm: what works? London: Free Association Books, 1997:72-84.

\section{Images in emergency medicine}

\section{Phlegmasia cerulea dolens, a rare complication of deep vein thrombosis}

A 73-year-old man with a history of bronchial adenocarcinoma with metastases to the brain, liver and vertebrae presented to our emergency medicine department. He had a history of an acutely painful swollen left leg with bluish discolouration of the foot (fig 1). He had been admitted 1 month earlier with multiple pulmonary emboli and had been given warfarin; no deep vein thrombosis was found at that time. Peripheral pulses were not palpable and capillary refill time was prolonged. Doppler ultrasound revealed thrombus extending from the popliteal vein proximally to the left external iliac vein.

Phlegmasia cerulea dolens, first recognised 400 years ago by Fabricius
Hildanus, is a rare and often devastating complication of deep vein thrombosis with a reported mortality of $25 \%$; amputation is required in $25 \%$ of those who survive. ${ }^{1}$ It results from thrombosis involving both major deep venous channels of the extremity and collateral veins, resulting in venous congestion with massive fluid sequestration and severe oedema, resulting in arterial compromise.

\section{R M Cooper, S A Hayat}

Countess of Chester Hospital, Chester, UK

Correspondence to: Dr R M Cooper, Countess of Chester NHS Trust, 175 Queens Road, Chester CH1 3BF, UK; robcooper@doctors.net.uk

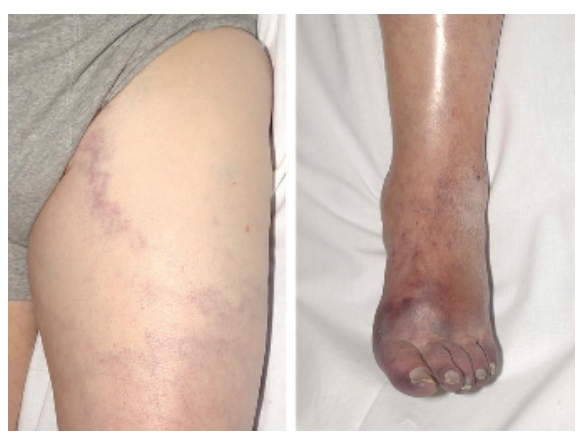

Figure 1 Swollen left leg with bluish discolouration of the foot.

Patient consent: Patient consent has been received for publication of the details of this case.

Emerg Med J 2008;25:334.

doi:10.1136/emj.2007.053330

\section{REFERENCE}

1. Perkins J, Magee TR, Galland RB. Phlegmasia cerulea dolens and venous gangrene. Br J Surg 1996;83:19. 


\section{EM]}

\section{Could inter-agency working reduce emergency department attendances due to alcohol consumption?}

$\mathrm{J}$ Benger and R Carter

Emerg Med J 2008 25: 331-334

doi: 10.1136/emj.2007.048926

Updated information and services can be found at:

http://emj.bmj.com/content/25/6/331.full.html

These include:

References This article cites 1 articles, 1 of which can be accessed free at: http://emj.bmj.com/content/25/6/331.full.html\#ref-list-1

Article cited in:

http://emj.bmj.com/content/25/6/331.full.html\#related-urls

Email alerting Receive free email alerts when new articles cite this article. Sign up in service the box at the top right corner of the online article.

Topic Articles on similar topics can be found in the following collections Collections

Notes

To request permissions go to:

http://group.bmj.com/group/rights-licensing/permissions

To order reprints go to:

http://journals.bmj.com/cgi/reprintform

To subscribe to BMJ go to:

http://group.bmj.com/subscribe/ 